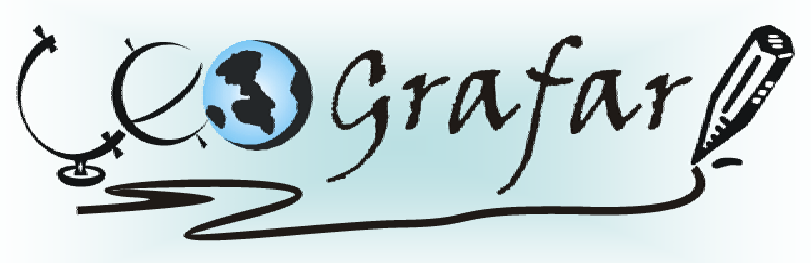

Revista Eletrônica do Programa de Pós-Graduação em Geografia - UFPR

\title{
A UTILIZAÇÃO DO MÉTODO DE VEN TE CHOW - SOIL CONSERVATION SERVICE (SCS) NA ESTIMATIVA DA VAZÃO MÁXIMA DA BACIA HIDROGRÁFICA DO RIO ATUBA
}

\author{
FABRIZIA GIOPPO NUNES ${ }^{1}$ ALBERTO PIO FIORI ${ }^{2}$
}

\begin{abstract}
RESUMO: A falta de dados fluviométricos consistentes e representativos vem sendo um dos maiores problemas enfrentados durante a análise e avaliação do regime hidrológico, de bacias hidrográficas brasileiras. Desta forma, os modelos de transformação de chuvas em vazões, tornam-se fundamentais para um país que possui poucos dados fluviométricos. O presente estudo visa avaliar a variação da vazão máxima da bacia hidrográfica do rio Atuba, em três períodos distintos de urbanização: a) início da década de 60, ano de 1962, quando a bacia estava quase que em seu estado natural; b) ano de 1980, início do processo de urbanização e; c) ano 2000, período em que se observa um acelerado aumento das regiões urbanas. Durante a simulação da vazão máxima foi utilizado o método de Ven Te Chow - Soil Conservation Service (SCS) que é um modelo hidrológico de transformação de chuvas em vazões. Para a aplicação do modelo hidrológico foi necessário confeccionar através da técnica de fotointerpretação digital, mapas da cobertura superficial do terreno dos anos de 1962, 1980 e 2000 além da determinação de alguns parâmetros hidrológicos tais como: precipitação excedente, intensidade da chuva, número de deflúvio, fator de redução de pico do hidrograma e grupos hidrológicos dos solos. Como resultado final obteve-se a quantificação das classes temáticas da cobertura superficial do terreno e da vazão máxima para os três anos analisados. Sendo a vazão máxima simulada em tempos de recorrência de 5, 10, 15 e 20 anos.
\end{abstract}

Palavras chaves: bacia hidrográfica do Atuba, vazão máxima, modelo hidrológico, urbanização.

\section{VEN TE CHOW METHOD - SOIL CONSERVATION SERVICE (SCS) APPLIED TO ESTIMATE THE MAXIMUM DISCHARGE OF ATUBA RIVER BASIN}

\begin{abstract}
The lack of representatives and consistents fluviometirc data avaiables for Brazilian hydrographic basins normaly creates several difficulties during analysis of these systems. In this context, the rainfall and runoff methods are arising as essential and powerful tools to estimate maximum discharge of basins. In this work, the maximum discharge of Atuba river basin was under study during three diferents periods of urbanization: $a$ ) beginer of 60 years, when the basin could be considered in its natural state; $b$ ) in 1980 during the initial process of urbanization and $c$ ) in 2000 when some areas of the basin remains close to the natural state but is easy to observe a quick increasing in urbanization. The Ven Te Chow method applied in this study is based on urbanization impact over drainage systems. For this study in particular, were created land cover maps from the digital photointerpretation of aerial photos available for the years 1962, 1980 and 2000. After that, parameters such as effective precipitation, rainfall intensity, runoff number, reduction factor of hydrogram peack and hydrologic group of soil were estimated. As a final result, quantitative determinatations of land cover classes and maximum discharge in 5-, 10-, 15- and 20-year annual base-flow-recurrences were obtained.
\end{abstract}

Key-words: Atuba river basin, maximum discharge, hydrologic model, urbanization.

\footnotetext{
${ }^{1}$ Doutora em Geologia Ambiental pela Universidade Federal do Paraná, e-mail: fabrizia@ufpr.com.br

${ }^{2}$ Professor doutor do Depto de Geologia da Universidade Federal do Paraná, e-mail: fiori@ufpr.br
} 


\section{INTRODUÇÃO}

A cidade de Curitiba e seus núcleos marginais apresentam um amplo registro de inundações ao longo de sua história. No período compreendido entre 1911 até os dias atuais foram registrados diversos episódios pluviais intensos, provocando, em determinados lugares, inundações com ocorrência de grande número de desabrigados e de incalculáveis danos materiais para o poder público e a população local.

Estudos realizados por LIMA (2000), revelam que os principais desastres naturais em Curitiba e Região Metropolitana são as inundações e os alagamentos, correspondendo a mais de 40\% de todos os acidentes naturais registrados entre 1976 a 1999.

No que se refere às áreas sujeitas as inundações, uma avaliação e identificação mais detalhada do aumento da descarga de um rio e sua capacidade de suportar tal descarga, podem levar a um melhor planejamento urbano de uma cidade, com a redução de danos físicos e econômicos à população local e à administração pública.

Segundo TUCCI et al. (1993), a vazão máxima de uma bacia hidrográfica pode ser estimada com base: a) no ajuste de uma distribuição estatística de dados de vazões existentes; b) na regionalização (transposição) de dados de vazões de bacias circunvizinhas e; c) na transformação de chuvas em vazões.

Perante a pequena série histórica de vazões máximas monitoradas e disponíveis pela estação do Autódromo, situada a jusante do rio Atuba, que permitissem um estudo estatístico confiável das vazões máximas anuais, o presente estudo teve por objetivo principal a aplicação do método de Ven Te Chow que é um modelo hidrológico de transformação de chuvas em vazões. Este estudo visa avaliar a variação da vazão máxima da bacia hidrográfica do rio Atuba em três períodos distintos:

a) início da década de 60, ano de 1962, quando a urbanização ocupava apenas 0,57\% da área total da bacia, estando esta quase que em seu estado natural;

b) ano de 1980, início do processo de urbanização e;

c) ano 2000, período em que se observa um acelerado aumento das regiões urbanas com a intensificação da impermeabilização do solo;

A falta de dados fluviométricos consistentes e representativos vem sendo um dos maiores problemas enfrentados durante a análise e avaliação do regime hidrológico de bacias 
hidrográficas brasileiras, tornando-se assim, os modelos de transformação de chuvas em vazões, fundamentais para um país que possui poucos dados fluviométricos.

O método proposto por Ven Te Chow tem sido utilizado em estimativas de vazões máximas, ou seja, das vazões de projeto para previsão de enchentes e elaboração de obras hidráulicas. A estimativa das vazões de projeto é feita com base nos dados de chuvas intensas que ocorrem na respectiva bacia em estudo. O método utiliza as hipóteses de hidrograma unitário, considerando que o fenômeno de transformação da chuva em vazão é regido por equações lineares. No método as vazões máximas são proporcionais às chuvas efetivas.

Neste método a chuva efetiva, ou seja, a chuva excedente é a maior responsável pelas vazões de cheias principalmente em bacias de pequenas escalas e urbanizada. A impermeabilização do solo, que normalmente é acompanha pelo processo de urbanização, é a principal geradora da alteração da parcela da chuva que escoa superficialmente.

\section{ÁREA DE ESTUDO}

A bacia hidrográfica do rio Atuba possui uma área total de drenagem de 127,43 $\mathrm{km}^{2} \mathrm{e}$ está situada no Primeiro Planalto Paranaense, entre as coordenadas de $25^{\circ} 17^{\prime} 00^{\prime \prime}$ e $25^{\circ} 30^{\prime}$

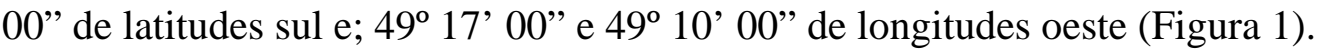

FIGURA 1- MAPA ILUSTRATIVO DA LOCALIZAÇÃO DA ÁREA DE ESTUDO.

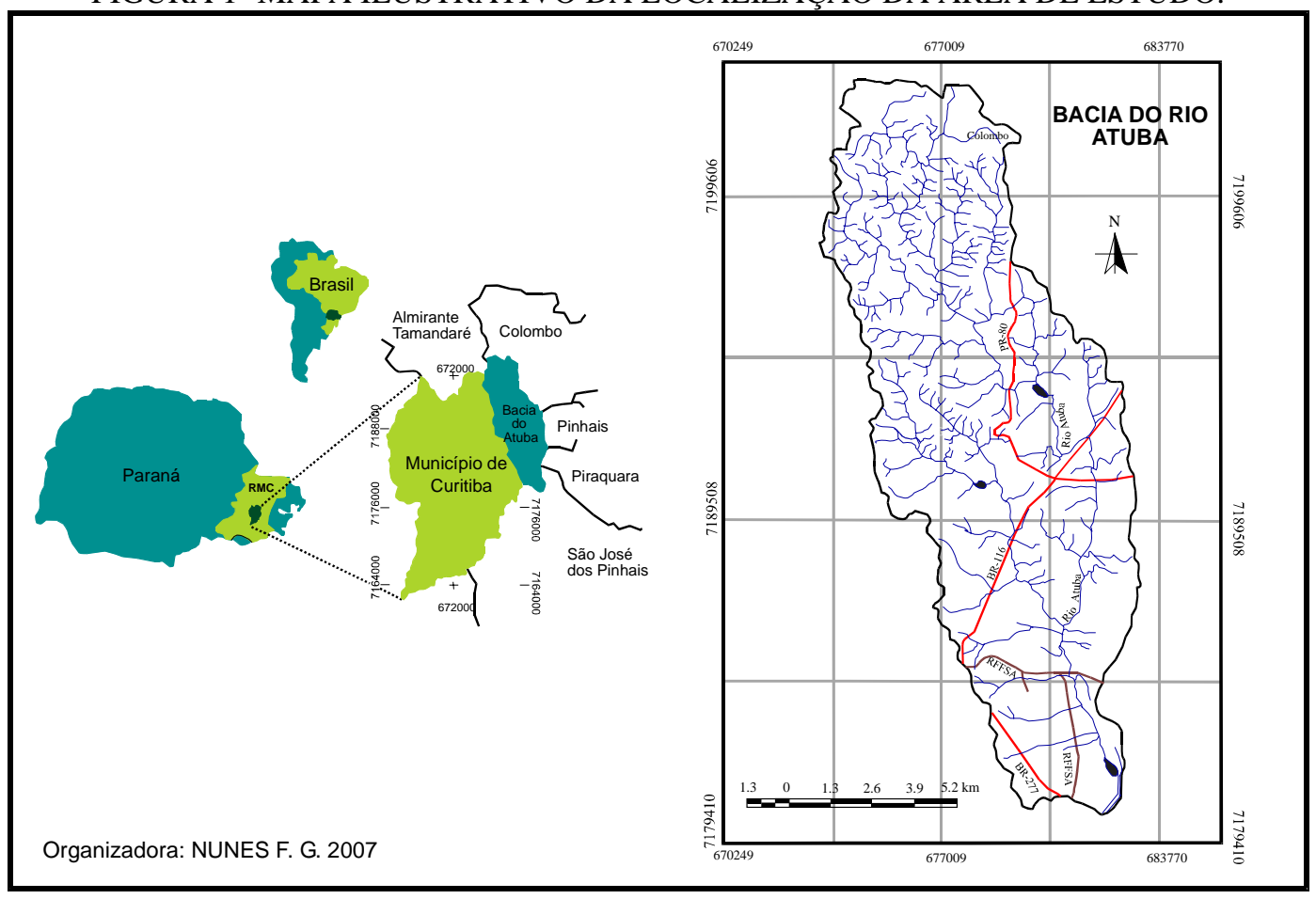


O seu canal principal, que é um dos afluentes da margem direita do rio Iguaçu, mede cerca de 32,45 km de extensão e o seu canal secundário, denominado rio Bacacheri, tem 12,5 km de comprimento.

Em quase toda a sua extensão pode ser verificado o processo de urbanização acelerada, sendo a bacia do rio Atuba considerada como a segunda bacia mais urbanizada de Curitiba e suas imediações, apresentando grande parte do seu médio e baixo curso canalizado com trechos retificados.

Suas nascentes encontram-se no município de Colombo na região Serrana do Açungui, com altitude aproximada de $1.000 \mathrm{~m}$. Desenvolve-se no sentido $\mathrm{N}-\mathrm{S}$ até chegar à sua foz no rio Iguaçu, a 875 m de altitude, no município de São José dos Pinhais.

Como suas principais características geomorfológicas tem-se a presença das maiores declividades em suas cabeceiras, onde se verificam os afluentes de pequenas extensões. As menores declividades encontram-se na região do baixo curso, sobre os terrenos encharcados, com rios de longas extensões.

A geologia é formada por rochas metamórficas e plutônicas correspondentes aos mármores, filitos, quartzitos e migmatitos-ginassicos, cortadas por diques de rochas básicas. Depósitos recentes do quaternário-terciário são verificados ao longo das margens do rio principal, constituídos por terrenos aluvionares e coluvionares.

Os Latossolos são predominantes na área da bacia, com perfis profundos, textura argilosa, bem porosos e drenados. Localizam-se principalmente nas regiões das declividades menos acentuadas, onde os depósitos das encostas são mais espessos. Nas áreas das maiores declividades, ocorrem os Cambissolos que também são solos com textura argilosa, bem poros e drenados, porem, com perfis de menor profundidade.

Ao longo das margens do rio principal e junto à sua foz, onde a circulação da água é baixa, são verificados os solos Hidromórficos e Orgânicos.

\section{MATERIAIS E MÉTODO}

Durante o trabalho foram coletados diversos elementos que permitiram a caracterização fisiográfica da bacia, como plantas topográficas, levantamentos aerofotogramétricos, carta geológica e de solos disponíveis para a região. 
Através da técnica de fotointerpretação digital, utilizando a função “Stereo Analyst” do software Erdas Imagine versão 8.6, foi possível interpretar fotografias aéreas de diferentes datas de aquisição, para a confecção dos mapas de cobertura superficial do terreno dos três períodos analisados.

Concluída a interpretação das fotografias aéreas, os dados gerados foram transferidos para o software Spring onde foi realizando um mosaico de todos os polígonos digitalizados e as medidas de suas áreas, de acordo com cada classe temática, atribuída durante as suas classificações. Este procedimento serviu para a análise da alteração da cobertura superficial do terreno e para a aplicação do modelo hidrológico elaborado por Ven Te Chow.

\section{Método de Ven Te Chow - Soil Conservation Service (SCS)}

O método de Ven Te Chow foi aplicado conforme preconizado na publicação de WILKEN (1971), tendo por base a seguinte relação:

$$
Q_{\max }=\frac{A \cdot X \cdot Y \cdot Z}{3,6}
$$

onde:

$\mathrm{Q}_{\max }=$ vazão máxima em $\mathrm{m}^{3} / \mathrm{s}$;

A = área da bacia, sendo igual a 127,43 $\mathrm{km}^{2}$;

$X=$ fator de deflúvio, sendo igual a razão da precipitação excedente pela duração $\left(X=R e / t_{d}\right)$; $\mathrm{Y}=\mathrm{o}$ fator climático, sendo igual a 1 , já que a equação das chuvas intensas utilizada no trabalho, foi elaboração para a região da área em estudo (região de Curitiba);

$\mathrm{Z}$ = fator de redução do tempo de pico;

Uma vez que o fator de deflúvio "X” é a razão da chuva excedente pela duração, para o cálculo do excesso da chuva foi utilizada a fórmula do Soil Conservation Service, sedo aplicada somente após a determinação da chuva total e do número de deflúvio.

Como a duração da chuva para a qual a vazão será máxima é desconhecida, durante os cálculos das vazões máximas pelo Método de Ven Te Chow foi necessário adotar um procedimento tentativo, conforme o descrito a seguir:

$1^{\circ}$ - arbitraram-se valores para a duração da chuva (td);

$2^{\circ}$ - para cada valor arbitrado foi obtida a intensidade da chuva ( $\left.\mathrm{i}_{\mathrm{m}}\right)$ a partir de uma equação de intensidade-duração-freqüência. 
$3^{\circ}$ - calculou-se a chuva total correspondente a cada duração e em relação a diferentes tempos de recorrência $\left(R=i_{m} \cdot t d\right)$;

$4^{\circ}$ - verificou-se o número de deflúvio para cada ano analisado $(\mathrm{N})$, sendo estes, estipulados, igual aos valores de (CN) do método do SCS;

$5^{\circ}$ - calculou-se a precipitação excedente $(\mathrm{Re})$;

$6^{\circ}$ - calculou-se a intensidade da chuva excedente $(X=\mathrm{Re} / \mathrm{td})$;

$7^{0}$ - calcula-se o valor da razão (td/tp) para fixação do valor do fator de redução de pico;

$8^{\text {o }}$ - determinou-se o fator climático para a região em estudo, através de uma equação de IDF local e;

9- por fim, calculou-se a vazão máxima pela fórmula de Ven Te Chow (Equação 1);

O procedimento descrito acima foi repetido para todos os valores de duração da chuva arbitrados. A vazão máxima para cada um dos anos analisados, e em diferentes tempos de recorrência estipulados, foi aquela que resultou a máxima nos cálculos efetuados.

O Tempo de recorrência ou período de retorno é o período de tempo médio, medido em anos, em que um determinado evento deve ser igualado ou superado pelo menos uma vez. Neste trabalho foram selecionados quatro tempos de recorrência na determinação da chuva intensa, precipitação excedente e das vazões máximas, sendo ele: Tr de 5, 10, 15 e 20 anos.

\section{Precipitação Excedente (Re)}

A precipitação excedente utilizada durante a aplicação do Método de Ven Te Chow, foi calculada a partir da fórmula elaborada pelo Soil Conservation Service e, reescrita, no sistema métrico nacional por WILKEN (1971):

$$
\operatorname{Re}=\frac{(\mathrm{R}-5080 / \mathrm{N}+50,8)^{2}}{\mathrm{R}+20320 / \mathrm{N}-203,2}
$$

onde:

Re = precipitação excedente dada em mm;

$\mathrm{R}$ = chuva total, dada em mm, sendo igual à relação de $\mathrm{i}_{\mathrm{m}} \cdot \mathrm{td}$;

$\mathrm{N}$ = número de deflúvio que é considerado igual ao valor de $\mathrm{CN}$. 


\section{Intensidade da Chuva $\left(\mathbf{i}_{\mathrm{m}}\right)$}

A intensidade da chuva considerada na aplicação dos métodos que transformam precipitação em vazão é a intensidade máxima média observada num certo intervalo de tempo, para um período de retorno determinado, sendo um resultado do valor médio da chuva, no tempo e no espaço (TUCCI et al, 1993).

A intensidade da chuva para todos os tempos de duração arbitrados e tempos de recorrências analisados (Quadro 1) foi obtida através da aplicação da equação de I-D-F atualizada em 2000, para a estação de Curitiba - Prado Velho e indicada por FENDRICH (2003) conforme a relação a seguir.

$$
i_{m}=\frac{5 \cdot 726,64 \cdot T_{r}^{0,159}}{\left(t_{d}+41\right)^{1,041}}
$$

onde:

$\mathrm{i}_{\mathrm{m}}=$ intensidade máxima da chuva, em $\mathrm{mm} / \mathrm{h}$;

$\mathrm{T}_{\mathrm{r}}=$ tempo de recorrência em anos;

$\mathrm{t}_{\mathrm{d}}=$ tempo de duração da chuva, em min.

\begin{tabular}{|c|c|c|c|}
\hline td (min) & td (h) & $\mathbf{i}_{\mathrm{m}}(\mathrm{mm} / \mathrm{h})$ & $\mathbf{R}(\mathrm{mm})$ \\
\hline \multicolumn{4}{|l|}{ Tr 5 anos } \\
\hline 120 & 2,0 & 37,30 & 74,60 \\
\hline 150 & 2,50 & 31,22 & 78,05 \\
\hline 180 & 3,0 & 26,82 & 80,46 \\
\hline 210 & 3,50 & 23,50 & 82,25 \\
\hline 240 & 4,0 & 20,89 & 83,56 \\
\hline 270 & 4,50 & 18,80 & 84,60 \\
\hline \multicolumn{4}{|l|}{ Tr 10 anos } \\
\hline 120 & 2,0 & 41,65 & 83,30 \\
\hline 150 & 2,50 & 34,86 & 87,15 \\
\hline 180 & 3,0 & 29,95 & 89,85 \\
\hline 210 & 3,50 & 26,23 & 91,80 \\
\hline 240 & 4,0 & 23,32 & 93,28 \\
\hline 270 & 4,50 & 20,99 & 94,45 \\
\hline \multicolumn{4}{|l|}{ Tr 15 anos } \\
\hline 120 & 2,0 & 44,42 & 88,84 \\
\hline 150 & 2,50 & 37,18 & 92,95 \\
\hline 180 & 3,0 & 31,94 & 95,82 \\
\hline 210 & 3,50 & 27,98 & 97,93 \\
\hline 240 & 4,0 & 24,88 & 99,52 \\
\hline 270 & 4,5 & 22,38 & 100,71 \\
\hline \multicolumn{4}{|l|}{ Tr 20 anos } \\
\hline 120 & 2,0 & 46,50 & 93 \\
\hline 150 & 2,50 & 38,92 & 97,3 \\
\hline 180 & 3,0 & 33,44 & 100,32 \\
\hline 210 & 3,50 & 29,29 & 102,51 \\
\hline 240 & 4,0 & 26,04 & 104,16 \\
\hline 270 & 4,5 & 23,43 & 105,43 \\
\hline
\end{tabular}




\section{Número de Deflúvio (N)}

Para a determinação do número de deflúvio foi considerando tanto o tipo de cobertura superficial do terreno como o grupo hidrológico dos solos, sendo o valor de ' $\mathrm{N}$ ', determinado conforme o procedimento adotado para o cálculo do valor de CN descrito no método do Soil Conservation Service (SCS) in. TUCCI et al. (1995).

No método do SCS são considerados quatro grupos hidrológicos de solos, sendo eles:

Grupo A - solos com baixo potencial de deflúvio. Inclui areias em camadas profundas, com muito pouco silte ou argila, inferior a $8 \%$.

Grupo B - solos arenosos com camadas menos profundas que as do tipo A e com maior teor de argila total, porém ainda inferior a 15\%. Este grupo de solo em seu todo, tem uma capacidade de infiltração acima da média.

Grupo C - solos argilosos com teor total de argila de 20\% a 30\%, mas sem camadas argilosas impermeáveis ou contendo pedras, até a profundidade de 1,2 m. No caso das Terras Roxas, esses dois limites máximos podem ser de $40 \%$ e 1,5 m. Os solos do grupo C possuem baixa taxa de infiltração quando completamente úmidos.

Grupo D - solos argilosos, com 30\% a 40\% de argila total, com camada densificada a uns $50 \mathrm{~cm}$ de profundidade e quase impermeável. São solos com elevado potencial de escoamento e baixa taxa de infiltração.

Na bacia do rio Atuba, dos quadros grupos de solos descriminados pelo método do SCS forma identificado apenas dois tipos: o grupo de solos C constituídos pelos Latossolos, Cambissolos e Terra Roxa Estruturada e; o grupo de solos D constituído pelos solos Hidromórficos e Orgânicos.

Diversas classes de cobertura superficial do terreno foram estipuladas conforme o aglomerado de suas edificações e do tipo de uso e ocupação dos solos, objetivando assim, uma melhor análise do processo de urbanização na bacia do rio Atuba. As classes de cobertura superficial do terreno utilizadas foram modificadas e adaptadas do método do SCS in. TUCCI et al. (1995), de acordo com o descrito a seguir:

Edificação muito densa - que consiste nas partes centrais densamente construídas de uma cidade, com cerca de 85\% de impermeabilização do terreno;

Edificação não muito densa - que são as zonas residenciais adjacentes ao centro, de menor densidade de habitação que as regiões centrais, com cerca de $65 \%$ de impermeabilização do terreno; 
Edificações com superfícies livres - que são as zonas residenciais, com cerca de 38\% de impermeabilização do terreno;

Edificações com muitas superfícies livres - que são as zonas residenciais possuindo construções esparsas, com cerca de 30\% de impermeabilização do terreno;

Zonas industriais e comerciais - que consiste nas áreas industrias e barracões de comércios, com cerca de 72\% de impermeabilização do terreno;

Campo e áreas verdes - que são os parques com vegetação rasteira, campos de esportes, áreas cultivadas, áreas com gramados e terrenos desnudos e;

Zonas florestais e vegetação densa - que abrange todas as áreas com vegetação de portes arbóreos naturais ou reflorestadas em boas condições.

Os tipos de cobertura superficial do terreno, bem como a sua alteração ao longo dos três períodos estudados, puderam ser quantificados através dos mapas de cobertura superficial do terreno dos anos de 1962, 1980 e 2000 (Figura 2).

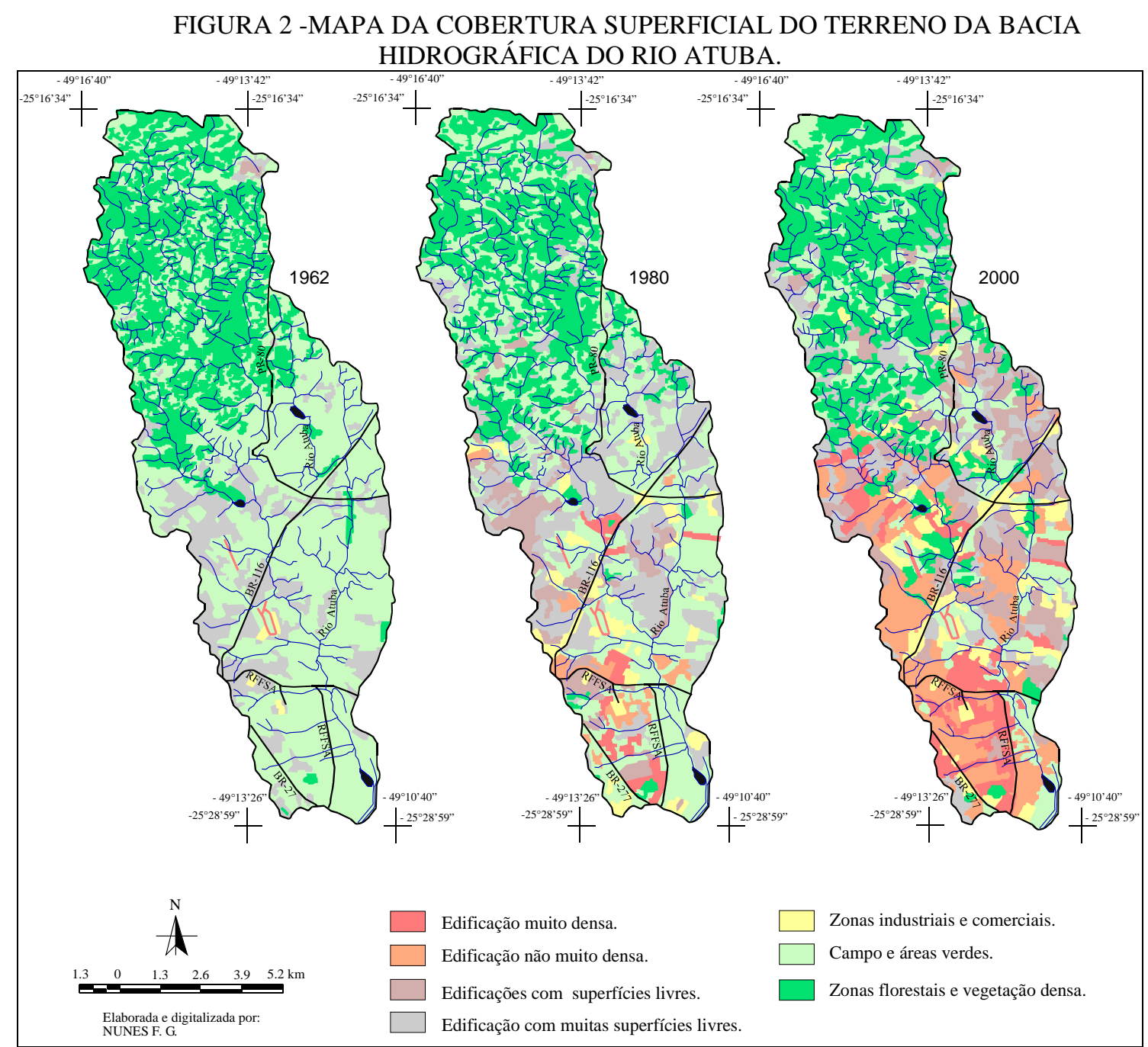


QUADRO 2 - ÁREAS DAS CLASSES DE COBERTURA SUPERFICIAL DO TERRENO DA BACIA HIDROGRÁFICA DO RIO ATUBA DOS ANOS 1962, 1980 e 2000.

\begin{tabular}{|c|c|c|c|c|c|c|}
\hline \multirow{4}{*}{ Descrição das Classes } & \multicolumn{6}{|c|}{ Área na bacia do Atuba /Anos } \\
\hline & \multirow{2}{*}{\multicolumn{2}{|c|}{$\begin{array}{c}1962 \\
\text { Total da classe }\end{array}$}} & \multicolumn{2}{|c|}{1980} & \multicolumn{2}{|c|}{2000} \\
\hline & & & Total & classe & Total & lasse \\
\hline & $\mathrm{km}^{2}$ & $\%$ & $\mathrm{~km}^{2}$ & $\%$ & $\mathrm{~km}^{2}$ & $\%$ \\
\hline Edificação muito densa. & 0,2032 & 0,16 & 3,1734 & 2,5 & 9,5618 & 7,5 \\
\hline Edificação não muito densa. & 0,0000 & 0,0 & 2,7991 & 2,2 & 18,607 & 14,6 \\
\hline Edificações com superfícies livres. & 0,2651 & 0,21 & 9,0061 & 7,0 & 17,789 & 14 \\
\hline $\begin{array}{l}\text { Edificações com muitas superfícies } \\
\text { livres. }\end{array}$ & 15,755 & 12,3 & 27,016 & 21,2 & 15,250 & 11,9 \\
\hline Zonas industriais e comerciais. & 0,2400 & 0,2 & 4,6833 & 3,7 & 8,2301 & 6,4 \\
\hline Campo e áreas verdes. & 76,543 & 60,1 & 53,638 & 42,1 & 27,109 & 21,2 \\
\hline Zonas florestais e vegetação densa. & 34,367 & 26,9 & 27,050 & 21,2 & 30,747 & 24,1 \\
\hline Corpos d’água. & 0,0605 & 0,05 & 0,0605 & 0,05 & 0,1397 & 0,11 \\
\hline Área total das classes & 127,43 & 100 & 127,43 & 100 & 127,43 & 100 \\
\hline
\end{tabular}

Segundo OSTA (1997) o valor de CN é compreendido entre zero e 100, sendo zero a representação de uma bacia de condutividade hidráulica infinita e 100 o valor correspondente a uma bacia totalmente impermeável. No Quadro 3 são apresentados os valores de CN para cada tipo de cobertura superficial do terreno e grupos hidrológicos de solos.

QUADRO 3 - VALORES DE CN EM FUNÇÃO DA COBERTURA SUPERFICIAL DO TERRENO E DOS GRUPOS HIDROLÓGICOS DE SOLOS.

\begin{tabular}{|c|c|c|c|c|}
\hline \multirow[b]{2}{*}{ Tipo de cobertura superficial do terreno } & \multicolumn{4}{|c|}{ Grupo hidrológico dos solos } \\
\hline & $\mathrm{A}$ & $\mathrm{B}$ & $\mathrm{C}$ & $\mathrm{D}$ \\
\hline $\begin{array}{l}\text { Edificação muito densa, com cerca de } 85 \% \text { de } \\
\text { impermeabilização. }\end{array}$ & 89 & 92 & 94 & 95 \\
\hline $\begin{array}{l}\text { Edificação não muito densa, com cerca de } 65 \% \text { de } \\
\text { impermeabilização. }\end{array}$ & 77 & 85 & 90 & 92 \\
\hline $\begin{array}{l}\text { Edificações com superfícies livres, com cerca de } 38 \% \text { de } \\
\text { impermeabilização. }\end{array}$ & 61 & 75 & 83 & 87 \\
\hline $\begin{array}{l}\text { Edificações com muitas superfícies livres, com } \\
\text { construções esparsas com cerca de } 30 \% \text { de } \\
\text { impermeabilização. }\end{array}$ & 57 & 72 & 81 & 86 \\
\hline $\begin{array}{l}\text { Zonas industriais e comerciais, com cerca de } 72 \% \text { de } \\
\text { impermeabilização. }\end{array}$ & 81 & 88 & 91 & 93 \\
\hline Campo e áreas verdes. & 30 & 58 & 71 & 78 \\
\hline Zonas florestais e vegetação densa. & 36 & 60 & 73 & 79 \\
\hline
\end{tabular}

Fonte: modificado e adaptado de TUCCI et al. (1995).

Como a bacia apresenta diferentes tipos de solos e de cobertura superficial, foi necessário adotar um único valor de CN para cada ano, obtido pela média ponderada dos diversos valores de CNs correspondentes às suas áreas homogêneas.

Assim, os valores de CN foram determinados pelo produto da participação percentual de cada grupo hidrológico de solos pelos respectivos valores do produto do percentual da área de 
cada tipo de cobertura superficial do terreno. $\mathrm{O}$ valor de $\mathrm{CN}$ médio adotado corresponde à somatória dos valores dos CNs parciais.

Para a bacia do rio Atuba os valores dos CN médio, ou seja, os valores do número de deflúvio (N) calculados foram: 73,20 para 1962; 76,50 para 1980; 80,57 para 2000.

A partir da determinação dos valores do número de deflúvio e da intensidade da chuva calculou-se, através da Equação 2, os valores da precipitação excedente para os anos de 1962, 1980 e 2000 em $\operatorname{Tr}(\mathrm{s})$ de 5, 10, 15 e 20 anos (Quadro 4).

QUADRO 4 - VALORES DA PRECIPITAÇÃO EXCEDENTE - RE (mm).

\begin{tabular}{|c|c|c|c|c|}
\hline td (h) & $\operatorname{Tr} 5$ & $\operatorname{Tr} 10$ & $\operatorname{Tr} 15$ & $\operatorname{Tr} 20$ \\
\hline \multicolumn{5}{|l|}{1962} \\
\hline 2,0 & 21,05 & 26,55 & 30,23 & 33,07 \\
\hline 2,50 & 23,18 & 29,09 & 33,03 & 36,07 \\
\hline 3,0 & 24,71 & 30,91 & 35,03 & 38,22 \\
\hline 3,50 & 25,86 & 32,24 & 36,52 & 39,80 \\
\hline 4,0 & 26,72 & 33,36 & 37,65 & 41,00 \\
\hline 4,5 & 27,40 & 34,07 & 38,50 & 41,93 \\
\hline \multicolumn{5}{|l|}{1980} \\
\hline 2,0 & 25,40 & 31,45 & 35,46 & 38,54 \\
\hline 2,50 & 27,76 & 34,22 & 38,50 & 41,79 \\
\hline 3,0 & 29,44 & 36,20 & 40,66 & 44,10 \\
\hline 3,50 & 30,70 & 37,64 & 42,27 & 45,79 \\
\hline 4,0 & 31,63 & 38,75 & 43,48 & 47,08 \\
\hline 4,5 & 32,38 & 39,63 & 44,40 & 48,07 \\
\hline \multicolumn{5}{|l|}{2000} \\
\hline 2,0 & 31,45 & 38,15 & 42,56 & 45,92 \\
\hline 2,50 & 34,08 & 41,20 & 45,88 & 49,44 \\
\hline 3,0 & 35,94 & 43,37 & 48,22 & 51,94 \\
\hline 3,50 & 37,33 & 44,94 & 49,96 & 53,77 \\
\hline 4,0 & 38,36 & 46,15 & 51,28 & 55,15 \\
\hline 4,5 & 39,18 & 47,10 & 52,27 & 56,22 \\
\hline
\end{tabular}

\section{FATOR DE REDUÇÃO DE PICO (Z)}

Segundo WILKEN (1971) o fator de redução de pico é a relação entre o pico de vazão de um hidrograma unitário, devido à chuva de uma dada duração, e o deflúvio da mesma intensidade de chuva, continuando indefinidamente.

Fazendo-se uso de dados de chuvas e de picos de vazão de cheias contribuintes de 20 bacias hidrográficas de pequena escala, do meio oeste dos Estados Unidos, Ven Te Chow na elaboração de seu método, buscou a correlação entre o tempo de duração de uma chuva considerada e a razão entre o fator de ascensão de pico, gerada por esta chuva “td/ $\mathrm{t}_{\mathrm{p}}$ ", para determinar o valor de “Z”. 
Uma vez que é necessário conhecer o valor do tempo de pico da vazão do hidrograma unitário " $\mathrm{t}_{\mathrm{p}}$ ” para se obter valores de “Z”, o valor de “ $\mathrm{t}_{\mathrm{p}}$ ” para a bacia hidrográfica do rio Atuba foi determinado pela equação elaborada por Ven Te Chow e adaptada por WILKEN (1971). O pesquisador (1971), determinou o tempo de ascensão de pico " $\mathrm{t}_{\mathrm{p}}$ ”, através de uma correlação do comprimento e da declividade do curso d’água, obtendo a seguinte relação:

$$
t_{p}=0,005055 \cdot\left(\frac{L}{\sqrt{I}}\right)^{0,64}
$$

no qual:

$t_{p}$ é o tempo de pico da vazão em horas, igual a “4,2 horas”, calculado para o rio Atuba;

L é o comprimento do curso d’água principal, medido em linha reta, sendo igual a $23.500 \mathrm{~m}$ para o rio Atuba e;

I é a declividade média do curso d’água principal em percentagem, sendo igual a 0,42\%, para o rio Atuba.

A declividade média do curso d’água do rio Atuba foi verificada através da confecção do perfil longitudinal, do fundo de vale do seu canal principal (Figura 3).

\section{FIGURA 3 - PERFIL LONGITUDINAL DO FUNDO DE VALE DO RIO ATUBA.}

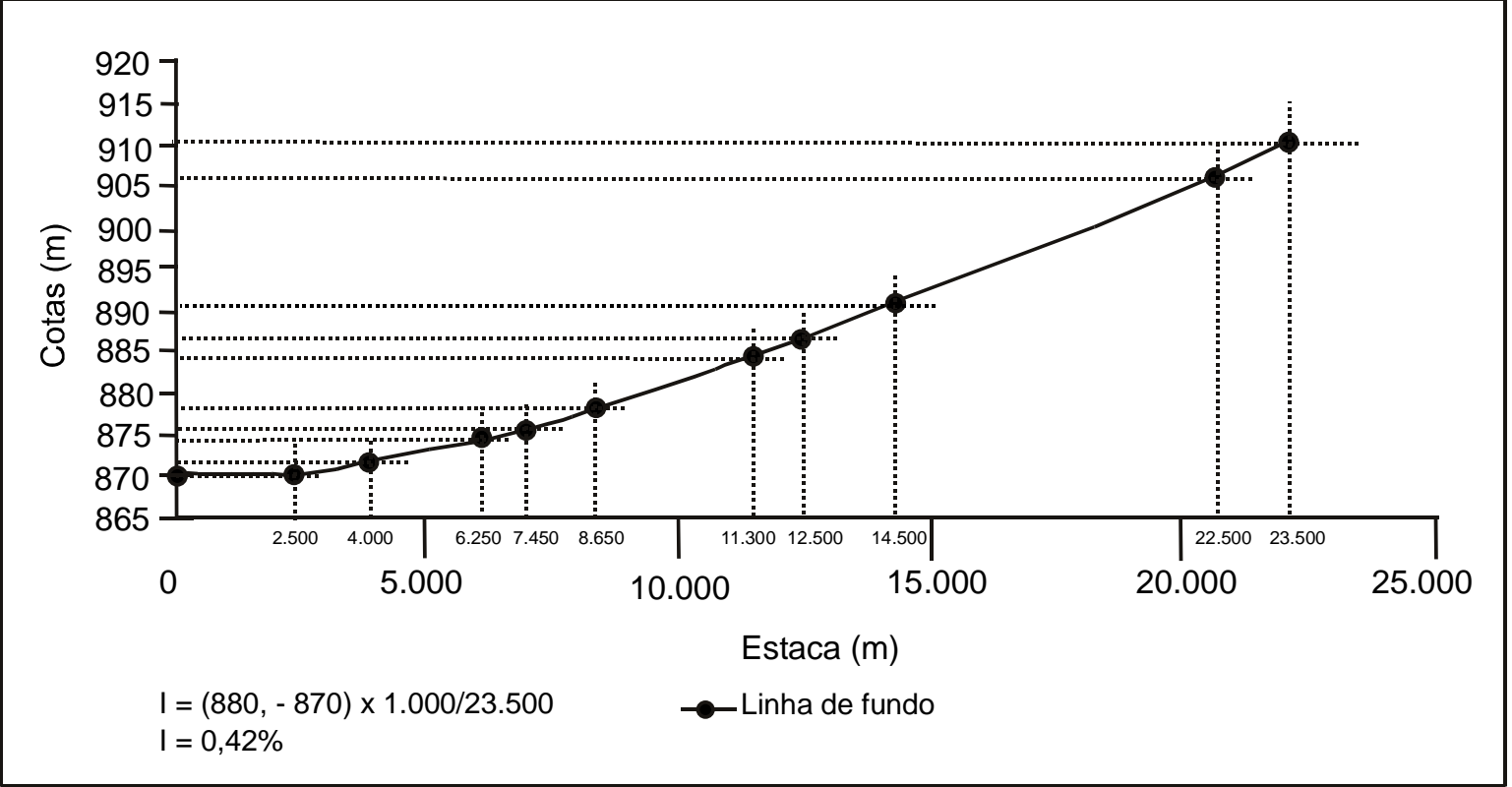

Os dados do fator "Z" utilizados no trabalho foram extraídos da tabela de fator de redução do tempo de pico de vazão, produzida por WILKEN (1971). Este dado fornece os valores de “Z” em função da relação td/t $\mathrm{t}_{\mathrm{p}}$ (Quadro 5). 
QUADRO 5 - FATOR DE REDUÇÃO DO TEMPO DE PICO DE VAZÃO.

\begin{tabular}{|c|c|c|c|c|c|c|c|c|c|}
\hline \multicolumn{10}{|c|}{ Valores de $\mathrm{Z}$ em função da relação $\mathrm{td} / \mathrm{t}_{\mathrm{p}}$} \\
\hline$t d / t_{p}$ & $\mathbf{Z}$ & $\mathbf{t d} / \mathrm{t}_{\mathrm{p}}$ & $\mathbf{Z}$ & $t d / t_{p}$ & $\mathbf{Z}$ & $\mathbf{T d} / \mathbf{t}_{\mathrm{p}}$ & $\mathbf{Z}$ & $t d / t_{p}$ & $\mathbf{Z}$ \\
\hline 0,05 & 0,04 & 0,46 & 0,36 & 0,84 & 0,58 & 1,22 & 0,75 & 1,60 & 0,90 \\
\hline 0,10 & 0,08 & 0,48 & 0,38 & 0,86 & 0,59 & 1,24 & 0,76 & 1,62 & 0,90 \\
\hline 0,12 & 0,10 & 0,50 & 0,39 & 0,88 & 0,50 & 1,26 & 0,77 & 1,64 & 0,91 \\
\hline 0,14 & 0,12 & 0,52 & 0,40 & 0,90 & 0,60 & 1,28 & 0,78 & 1,66 & 0,91 \\
\hline 0,16 & 0,14 & 0,54 & 0,41 & 0,92 & 0,61 & 1,30 & 0,79 & 1,68 & 0,92 \\
\hline 0,18 & 0,16 & 0,56 & 0,42 & 0,94 & 0,62 & 1,32 & 0,80 & 1,70 & 0,92 \\
\hline 0,20 & 0,18 & 0,58 & 0,44 & 0,96 & 0,63 & 1,34 & 0,81 & 1,72 & 0,93 \\
\hline 0,22 & 0,19 & 0,60 & 0,45 & 0,98 & 0,64 & 1,36 & 0,82 & 1,74 & 0,93 \\
\hline 0,24 & 0,20 & 0,62 & 0,46 & 1,00 & 0,65 & 1,38 & 0,82 & 1,76 & 0,94 \\
\hline 0,26 & 0,22 & 0,64 & 0,47 & 1,02 & 0,66 & 1,40 & 0,82 & 1,78 & 0,94 \\
\hline 0,28 & 0,24 & 0,66 & 0,48 & 1,04 & 0,67 & 1,42 & 0,83 & 1,80 & 0,95 \\
\hline 0,30 & 0,25 & 0,68 & 0,49 & 1,06 & 0,68 & 1,44 & 0,84 & 1,82 & 0,95 \\
\hline 0,32 & 0,26 & 0,70 & 0,50 & 1,08 & 0,69 & 1,46 & 0,85 & 1,84 & 0,96 \\
\hline 0,34 & 0,28 & 0,72 & 0,51 & 1,10 & 0,70 & 1,48 & 0,86 & 1,86 & 0,96 \\
\hline 0,36 & 0,29 & 0,74 & 0,52 & 1,12 & 0,71 & 1,50 & 0,86 & 1,88 & 0,97 \\
\hline 0,38 & 0,30 & 0,76 & 0,54 & 1,14 & 0,72 & 1,52 & 0,87 & 1,90 & 0,97 \\
\hline 0,40 & 0,32 & 0,78 & 0,55 & 1,16 & 0,73 & 1,54 & 0,88 & 1,92 & 0,98 \\
\hline 0,42 & 0,33 & 0,80 & 0,56 & 1,18 & 0,74 & 1,56 & 0,88 & 1,94 & 0,98 \\
\hline 0,44 & 0,34 & 0,82 & 0,57 & 1,20 & 0,74 & 1,58 & 0,89 & 1,96 & 0,99 \\
\hline
\end{tabular}

Fonte: WILKEN (1971).

\section{VALORES DA VAZÃO MÁXIMA DA BACIA DO RIO ATUBA OBTIDOS PELO MÉTODO DE VEM TE CHOW}

Como resultado final da aplicação do método elaborado por Ven Te Chow, são apresentadas nos Quadros 6, 7 e 8 as vazões máximas simuladas para a bacia hidrográfica do rio Atuba dos anos de 1962, 1980 e 2000 e em tempos de recorrência de 5, 10, 15 e 20 anos.

QUADRO 6 - VAZÃO MÁXIMA SIMULADA PELO MÉTODO DE VEN TE CHOW (ANO DE 1962).

\begin{tabular}{|c|c|c|c|c|c|c|c|}
\hline td (min) & td (h) & $\mathbf{i}_{\mathrm{m}}(\mathrm{mm} / \mathrm{h})$ & $\operatorname{Re}(\mathrm{mm} / \mathrm{h})$ & $t d / t p$ & $\mathbf{X}$ & $\mathbf{Z}$ & $\mathbf{Q}_{\max }\left(\mathrm{m}^{3} / \mathrm{s}\right)$ \\
\hline \multicolumn{8}{|l|}{ Tr 5 anos } \\
\hline 120 & 2,0 & 37,30 & 21,05 & 0,47 & 10,52 & 0,365 & 135,92 \\
\hline 150 & 2,50 & 31,22 & 23,18 & 0,59 & 9,27 & 0,445 & 146,02 \\
\hline 180 & 3,0 & 26,82 & 24,71 & 0,72 & 8,23 & 0,510 & 148,57 \\
\hline 210 & 3,50 & 23,50 & 25,86 & 0,83 & 7,38 & 0,575 & 150,21 \\
\hline 240 & 4,0 & 20,89 & 26,72 & 0,95 & 6,68 & 0,625 & 147,78 \\
\hline 270 & 4,5 & 18,80 & 27,40 & 1,07 & 6,08 & 0,685 & 147,42 \\
\hline \multicolumn{8}{|l|}{ Tr 10 anos } \\
\hline 120 & 2,0 & 41,65 & 26,55 & 0,47 & 13,27 & 0,365 & 171,44 \\
\hline 150 & 2,50 & 34,86 & 29,09 & 0,59 & 11,63 & 0,445 & 183,19 \\
\hline 180 & 3,0 & 29,95 & 30,91 & 0,72 & 10,30 & 0,510 & 185,94 \\
\hline 210 & 3,50 & 26,23 & 32,24 & 0,83 & 9,21 & 0,575 & 187,45 \\
\hline 240 & 4,0 & 23,32 & 33,36 & 0,95 & 8,34 & 0,625 & 184,51 \\
\hline 270 & 4,5 & 20,99 & 34,07 & 1,07 & 7,57 & 0,685 & 183,55 \\
\hline \multicolumn{8}{|l|}{ Tr 15 anos } \\
\hline 120 & 2,0 & 44,42 & 30,23 & 0,47 & 15,11 & 0,365 & 195,22 \\
\hline 150 & 2,50 & 37,18 & 33,03 & 0,59 & 13,21 & 0,445 & 208,08 \\
\hline 180 & 3,0 & 31,94 & 35,03 & 0,72 & 11,67 & 0,510 & 210,67 \\
\hline 210 & 3,50 & 27,98 & 36,52 & 0,83 & 10,43 & 0,575 & 212,28 \\
\hline 240 & 4,0 & 24,88 & 37,65 & 0,95 & 9,41 & 0,625 & 208,18 \\
\hline 270 & 4,5 & 22,38 & 38,50 & 1,07 & 8,55 & 0,685 & 207,31 \\
\hline
\end{tabular}




\begin{tabular}{|c|c|c|c|c|c|c|c|}
\hline Tr 20 anos & \multicolumn{7}{|l|}{$\mid$} \\
\hline 120 & 2,0 & 46,50 & 33,07 & 0,47 & 16,53 & 0,365 & 213,57 \\
150 & 2,50 & 38,92 & 36,07 & 0,59 & 14,43 & 0,445 & 227,30 \\
180 & 3,0 & 33,44 & 38,22 & 0,72 & 12,74 & 0,510 & 229,99 \\
210 & 3,50 & 29,29 & 39,80 & 0,83 & 11,37 & 0,575 & $\mathbf{2 3 1 , 4 2}$ \\
240 & 4,0 & 26,04 & 41,00 & 0,95 & 10,25 & 0,625 & 226,76 \\
270 & 4,5 & 23,43 & 41,93 & 1,07 & 9,32 & 0,685 & 225,98 \\
\hline
\end{tabular}

QUADRO 7 - VAZÃO MÁXIMA SIMULADA PELO MÉTODO DE VEN TE CHOW (ANO DE 1980).

\begin{tabular}{|c|c|c|c|c|c|c|c|}
\hline $\operatorname{td}(\mathrm{min})$ & td (h) & $\mathbf{i}_{\mathrm{m}}(\mathrm{mm} / \mathrm{h})$ & $\operatorname{Re}(\mathrm{mm} / \mathrm{h})$ & td/tp & $\mathbf{X}$ & $\mathbf{Z}$ & $\mathbf{Q}_{\max }\left(\mathrm{m}^{3} / \mathrm{s}\right)$ \\
\hline \multicolumn{8}{|l|}{ Tr 5 anos } \\
\hline 120 & 2,0 & 37,30 & 25,40 & 0,47 & 12,7 & 0,365 & 164,08 \\
\hline 150 & 2,50 & 31,22 & 27,76 & 0,59 & 11,10 & 0,445 & 174,84 \\
\hline 180 & 3,0 & 26,82 & 29,44 & 0,72 & 9,81 & 0,510 & 177,09 \\
\hline 210 & 3,50 & 23,50 & 30,70 & 0,83 & 8,77 & 0,575 & 178,50 \\
\hline 240 & 4,0 & 20,89 & 31,63 & 0,95 & 7,90 & 0,625 & 174,77 \\
\hline 270 & 4,5 & 18,80 & 32,38 & 1,07 & 7,19 & 0,685 & 174,33 \\
\hline \multicolumn{8}{|c|}{ Tr 10 anos } \\
\hline 120 & 2,0 & 41,65 & 31,45 & 0,47 & 15,72 & 0,365 & 203,10 \\
\hline 150 & 2,50 & 34,86 & 34,22 & 0,59 & 13,69 & 0,445 & 215,64 \\
\hline 180 & 3,0 & 29,95 & 36,20 & 0,72 & 12,06 & 0,510 & 217,71 \\
\hline 210 & 3,50 & 26,23 & 37,64 & 0,83 & 10,75 & 0,575 & 218,80 \\
\hline 240 & 4,0 & 23,32 & 38,75 & 0,95 & 9,68 & 0,625 & 214,15 \\
\hline 270 & 4,5 & 20,99 & 39,63 & 1,07 & 8,81 & 0,685 & 213,62 \\
\hline \multicolumn{8}{|l|}{ Tr 15 anos } \\
\hline 120 & 2,0 & 44,42 & 35,46 & 0,47 & 17,73 & 0,365 & 229,07 \\
\hline 150 & 2,50 & 37,18 & 38,50 & 0,59 & 15,40 & 0,445 & 242,58 \\
\hline 180 & 3,0 & 31,94 & 40,66 & 0,72 & 13,55 & 0,510 & 244,61 \\
\hline 210 & 3,50 & 27,98 & 42,27 & 0,83 & 12,08 & 0,575 & 245,87 \\
\hline 240 & 4,0 & 24,88 & 43,48 & 0,95 & 10,87 & 0,625 & 240,48 \\
\hline 270 & 4,5 & 22,38 & 44,40 & 1,07 & 9,86 & 0,685 & 239,07 \\
\hline \multicolumn{8}{|l|}{ Tr 20 anos } \\
\hline 120 & 2,0 & 46,50 & 38,54 & 0,47 & 19,27 & 0,365 & 248,97 \\
\hline 150 & 2,50 & 38,92 & 41,79 & 0,59 & 16,71 & 0,445 & 263,21 \\
\hline 180 & 3,0 & 33,44 & 44,10 & 0,72 & 14,70 & 0,510 & 265,37 \\
\hline 210 & 3,50 & 29,29 & 45,79 & 0,83 & 13,08 & 0,575 & 266,22 \\
\hline 240 & 4,0 & 26,04 & 47,08 & 0,95 & 11,77 & 0,625 & 260,39 \\
\hline 270 & 4,5 & 23,43 & 48,07 & 1,07 & 10,68 & 0,685 & 258,95 \\
\hline
\end{tabular}

QUADRO 8 - VAZÃO MÁXIMA SIMULADA PELO MÉTODO DE VEN TE CHOW (ANO DE 2000).

\begin{tabular}{|c|c|c|c|c|c|c|c|}
\hline td (min) & td (h) & $\mathbf{i}_{\mathrm{m}}(\mathrm{mm} / \mathrm{h})$ & $\operatorname{Re}(\mathrm{mm} / \mathrm{h})$ & $t d / t p$ & $\mathbf{X}$ & $\mathbf{Z}$ & $\mathbf{Q}_{\max }\left(\mathrm{m}^{3} / \mathrm{s}\right)$ \\
\hline \multicolumn{8}{|l|}{ Tr 5 anos } \\
\hline 120 & 2,0 & 37,30 & 31,45 & 0,47 & 15,73 & 0,365 & 203,23 \\
\hline 150 & 2,50 & 31,22 & 34,08 & 0,59 & 13,63 & 0,445 & 214,70 \\
\hline 180 & 3,0 & 26,82 & 35,94 & 0,72 & 11,98 & 0,510 & 216,27 \\
\hline 210 & 3,50 & 23,50 & 37,33 & 0,83 & 10,66 & 0,575 & 216,96 \\
\hline 240 & 4,0 & 20,89 & 38,36 & 0,95 & 9,59 & 0,625 & 212,16 \\
\hline 270 & 4,5 & 18,80 & 39,18 & 1,07 & 8,71 & 0,685 & 211,19 \\
\hline \multicolumn{8}{|c|}{ Tr 10 anos } \\
\hline 120 & 2,0 & 41,65 & 38,15 & 0,47 & 19,07 & 0,365 & 246,38 \\
\hline 150 & 2,50 & 34,86 & 41,20 & 0,59 & 16,48 & 0,445 & 259,60 \\
\hline 180 & 3,0 & 29,95 & 43,37 & 0,72 & 14,46 & 0,510 & 261,04 \\
\hline 210 & 3,50 & 26,23 & 44,94 & 0,83 & 12,84 & 0,575 & 261,34 \\
\hline 240 & 4,0 & 23,32 & 46,15 & 0,95 & 11,54 & 0,625 & 255,30 \\
\hline 270 & 4,5 & 20,99 & 47,10 & 1,07 & 10,47 & 0,685 & 253,86 \\
\hline
\end{tabular}




\begin{tabular}{|c|c|c|c|c|c|c|c|}
\hline Tr 15 anos & \multicolumn{7}{|l|}{$\mid$} \\
\hline 120 & 2,0 & 44,42 & 42,56 & 0,47 & 21,28 & 0,365 & 274,94 \\
150 & 2,50 & 37,18 & 45,88 & 0,59 & 18,35 & 0,445 & 289,04 \\
180 & 3,0 & 31,94 & 48,22 & 0,72 & 16,07 & 0,510 & 290,10 \\
210 & 3,50 & 27,98 & 49,96 & 0,83 & 14,27 & 0,575 & $\mathbf{2 9 0 , 4 4}$ \\
240 & 4,0 & 24,88 & 51,28 & 0,95 & 12,82 & 0,625 & 283,62 \\
270 & 4,5 & 22,38 & 52,27 & 1,07 & 11,61 & 0,685 & 281,50 \\
\hline Tr 20 anos & 2,0 & 46,50 & 45,92 & 0,47 & 22,96 & 0,365 & 296,64 \\
\hline 120 & $3,5,92$ & 49,44 & 0,59 & 19,77 & 0,445 & 311,41 \\
150 & 3,0 & 33,44 & 51,94 & 0,72 & 17,31 & 0,510 & 312,49 \\
180 & 3,50 & 29,29 & 53,77 & 0,83 & 15,36 & 0,575 & $\mathbf{3 1 2 , 6 3}$ \\
210 & 4,0 & 26,04 & 55,15 & 0,95 & 13,79 & 0,625 & 305,08 \\
240 & 4,5 & 23,43 & 56,22 & 1,07 & 12,49 & 0,685 & 302,84 \\
270 &
\end{tabular}

\section{CONCLUSÃO}

Os mapas de cobertura superficial do terreno revelam que a bacia hidrográfica do rio Atuba sofreu um grande processo de urbanização, no período compreendido entre 1980 a 2000.

A partir do ano de 1980, verifica-se o acelerado adensamento das áreas edificadas, com a transformação da classe de edificações com muitas superfícies livres para as classes de urbanização mais densas, como as classes de: edificação muito densa, edificação não muito densa e edificações com superfícies livres.

As áreas compreendidas por edificações com muitas superfícies livres que possuíam $15,75 \mathrm{~km}^{2}$, ou seja, 12,35\% de toda a área da bacia em 1962, no ano de 1980 aumenta para $27,016 \mathrm{~km}^{2}$ com $21,2 \%$ da área e, no ano de 2000 , diminui para $15,25 \mathrm{~km}^{2}$ com $11,95 \%$ de toda a bacia.

As edificações com superfícies livres, no ano de 1962 compreendiam 0,26km², perfazendo apenas 0,21\% da bacia do rio Atuba. Em 1980 esta classe cresce para 9,0km² com um percentual de $7 \%$. No ano de 2000 , aumenta para $17,78 \mathrm{~km}^{2}$, abrangendo $14 \%$ de toda a área.

A classe de edificação não muito densa surge somente a partir de 1980, somando uma pequena área de $2,79 \mathrm{~km}^{2}$ que representava somente 2,2\% da área de estudo. Em 2000 essa classe aumenta acentuadamente, passando para $18,607 \mathrm{~km}^{2}$, ocupando $14,6 \%$ do total da área.

Na classe de edificação muito densa, também se observa o seu crescimento acelerado no decorrer dos anos analisados. Em 1962 esta classe ocupava 0,20km², ou seja, 0,16\%. Em 
1980 aumenta para 3,17 $\mathrm{km}^{2}$ com 2,5\% e, em 2000 para 9,56 $\mathrm{km}^{2}$ com um total de 7,5\% de toda a área analisada.

No ano de 2000 os campos e áreas verdes diminuíram acentuadamente, passando a ocupar somente $27,10 \mathrm{~km}^{2}$, ou seja, $21,27 \%$ da área em estudo. Nota-se que esta classe aparecia bem distribuída por toda a bacia nos anos de 1962 e 1980, restringe-se, em 2000, quase que no seu total, às regiões do alto e médio curso da bacia.

A classe de zonas florestais e vegetação que em 1962 apresentava uma área de $34,36 \mathrm{~km}^{2}$ com um percentual de 26,96\%, em 1980 diminui para 27,05km², ou seja, para 21,25\% de área ocupada. Já no ano de 2000 observa-se uma pequena regeneração das zonas florestais e vegetação densa, passando esta classe, a possuir $30,74 \mathrm{~km}^{2}$ com $24,12 \%$ de toda a área da bacia.

O aumento das áreas urbanizadas veio a refletido diretamente na elevação das vazões de pico. Para um tempo de recorrência de 5 anos a vazão de pico elevou-se de 150,21 m³ em 1962 para 178,50 m³/s em 1980 e, para 216,96 m³/s em 2000. Já em um tempo de recorrência de 10 anos, a vazão de pico que era de 187,45 m³/s em 1962 aumentou para 218,80 m³ em 1980 e para $261,34 \mathrm{~m}^{3} / \mathrm{s}$ em 2000.

Mantendo-se ainda a mesma tendência de evolução para um tempo de recorrência de 15 anos, a vazão de pico de 212,28 m³/s em 1962 passa para 245,87 m³ $/ \mathrm{s}$ em 1980 e para 290,44 m³ em 2000. Para um tempo de recorrência de 20 anos, a vazões de pico de 231,42 $\mathrm{m}^{3} / \mathrm{s}$ em 1962 aumenta para 266,22 m³/s em 1980 e para 312,63 m³/s em 2000.

\section{AGRADECIMENTOS}

À Coordenação de Aperfeiçoamento de Pessoal de Nível Superior - CAPEs pela bolsa de doutorado, ao Conselho Nacional de Desenvolvimento Científico e Tecnológico - CNPq pela bolsa de doutorado sanduíche no exterior e ao Centro di Geotecnologie della Università degli Studi di Siena pelos conhecimentos e equipamentos utilizados durante a fase de fotointerpretação digital. 


\section{REFERÊNCIAS BIBLIOGRÁFICAS}

CHOW V. T. et al. Applied Hydrology. $1^{\text {a }}$ ed. New York, McGraw Hill, 1988.

EMBRAPA - EMPRESA BRASILEIRA DE PESQUISA AGROPECUÁRIA \& IAPAR FUNDAÇÃO INSTITUTO AGRONÔMICO DO PARANÁ. Levantamento de Reconhecimento dos Solos do Estado do Paraná: Tomos - I \& II. Convênio EMBRAPA/SUDESUL/ Governo do Estado do Paraná/IAPAR, Londrina - PR, 1984.

EMBRAPA - EMPRESA BRASILEIRA DE PESQUISA AGROPECUÁRIA \& IAPAR FUNDAÇÃO INSTITUTO AGRONÔMICO DO PARANÁ. Carta de Solos do Levantamento e Reconhecimento dos Solos do Estado do Paraná. Londrina -PR, Convênio EMBRAPA/SUDESUL/Governo do Estado do Paraná/IAPAR, escala 1:600.000, 1984.

FENDRICH R.; OBLADEN N. L.; AISSE M. M; GARCIAS C. M. Drenagem e Controle da Erosão Urbana. $4^{\text {a }}$ ed. Curitiba - PP, Editora Universitária Champagnat, 1997.

FENDRICH, R. Chuvas Intensas para Obras de Drenagem no Estado do Paraná. $2^{a}$ ed. rev. ampl. Curitiba - PR, Edição do autor, 2003.

INPE- PROGRAMA SPRING. Instituto de Pesquisas Espaciais, versão 4.2: Tutorial, São José dos Campos - SP, 2005, $1^{\circ}$ CD-ROM.

LIMA, R. E. Uso dos Solos e dos Rios: Conceitos Básicos e Aplicações para a Região de Curitiba - PR. $1^{\text {a }}$ ed. Curitiba - PR, Editora do NIMAD - UFPR,2000.

LOPES, J. A. U. Nota Explicativa da Folha Geológica de Curitiba. Boletim Geológico da UFPR - Contribuição da Comissão de Carta Geológica do Paraná. Curitiba - PR, n. 20, 1966.

OSTA A. J. S. T. da. A. Influência da Urbanização no Comportamento Hidrológico de Bacias de Drenagem - Município do Rio de Janeiro - RJ. Anais do VII Simpósio Brasileiro de Geografia Física Aplicada e I Fórum Latino-Americano de Geografia Física Aplicada. Curitiba - PR, Departamento de Geografia - UFPR, vol. 2, 1997,1 CD-ROM.

TUCCI C. E. M. et al. Hidrologia: Ciência Aplicação. $1^{a}$ ed. Porto Alegre -RS, Editora da UFRGS, ABRH, EDUSP, vol 4,1993.

TUCCI C. E. M. et al. (1995) Drenagem Urbana. $1^{\text {a }}$ ed. Porto Alegre - RS, Editora da UFRGS, 1995.

TUCCI, C. E. M; CLARKE, R. T. Impactos das Mudanças da Cobertura no Escoamento. Anais do I - Fórum Geo-Bio Hidrologia. Instituto de Pesquisa Hidráulica - IPH - UFRGS, Curitiba - PR, 1998.

WILKEN, P. S. Águas Pluviais: Contribuição ao Estudo dos Métodos de Dimensionamento de Estruturas Hidráulicas para o Esgotamento de Águas Pluviais. $1^{\text {a }}$ ed. São Paulo, Edição do autor, 1971. 